\title{
The Effect of Moderate Glycemic Energy Bar Consumption on Blood Glucose and Mood in Dancers
}

\author{
Derrick Brown, MSc, and Matthew Wyon, PhD
}

Ingesting quality carbohydrates has been shown to be essential for dancers. Given that most dance classes take place in the morning, it has been recommended that dancers eat a well-balanced breakfast containing carbohydrates, fats, and protein as a means of fuelling this activity. The aim of this study was to determine the effect of a moderate glycemic index energy (MGI) bar or a fasting condition on dancers' blood glucose levels and perceived pleasure-displeasure response during the first dance class of the day. In a randomized counterbalanced design, 10 female preprofessional dance students took their regular scheduled contemporary dance class, on four separate occasions. On each occasion, they consumed either a commercially prepared carbohydrate $(\mathrm{CHO})$ dense energy bar (47.3 g CHO) or water (FAST). Plasma glucose responses and pleasure-displeasure affect were measured before and at two time points during the class. Dancers who consumed the MGI bar had significantly greater peak blood glucose levels at all time points than those who fasted $(p<0.05)$. Regarding affective state measures, participants who had breakfast had significantly greater pleasure scores than those who only ingested water $(p<0.05)$. In conclusion, results suggest that $\mathrm{CHO}$ with an MGI value positively impacts blood glucose concentrations during a dance class. Further, we conclude that skipping breakfast can have an unfavorable effect on the pleasure-displeasure state of dancers. These findings highlight the impact of breakfast on how one feels, as well as the physiological and metabolic benefits of $\mathrm{CHO}$ as an exogenous energy source in dancers. Med Probl Perform Art 2014; 29(1):27-31.

$\mathrm{D}$ ance class, rehearsal, and stage performance all entail intermittent periods of high-intensity intermittent physical activity (HIIT). ${ }^{1,2}$ Therefore, dancers should ensure adequate energy reserves to perform their daily activities. ${ }^{3,4}$ A variety of factors determine which type of fuel muscles utilize during exercise ${ }^{5}$; however, it has long been established that performing athletes use carbohydrate $(\mathrm{CHO})$ as a primary energy source more than those leading an inactive lifestyle. ${ }^{6,7}$ The World Health Organization (WHO) recommends at least $55 \%$ of total energy come from

Mr. Brown is Associate Researcher at ArtEZ Institute of Arts and the National Centre for Performing Arts, Arnhem, the Netherlands; and Dr. Wyon is Research Professor at the Research Centre for Sport Exercise and Performance, University of Wolverhampton, Walsall, and National Institute of Dance Medicine and Science, UK.

Presented in part at the 22nd International Association of Dance Medicine $\mathcal{E}$ Science Symposium, Singapore, Oct 2012.

Address correspondence to: $\mathrm{Mr}$. Brown, ArtEZ Institute of the Arts, Onderlangs 9, 6812 CE Arnhem, the Netherlands. Tel +31655358027. De.Brown@artez.nl.

(C) 2014 Science $\mathcal{E}$ Medicine. www.sciandmed.com/mppa. a variety of $\mathrm{CHO}$ sources for optimum health, ${ }^{8}$ while for sporting populations the recommendation is $60 \% .^{9}$ From studies of dietary practices among elite and student dancers, and from the observations of dieticians, exercise physiologist, and sport nutritionists, the general consensus is that many dancers do not achieve the adequate nutrition needed for optimal physical health and performance. ${ }^{10-17}$ Nutrition often takes a subordinate role when aesthetic principles become more important than energy balance. ${ }^{18}$ Dancers' demanding schedules, in addition to a potential lack of nutritional knowledge, may also prohibit them from maintaining an optimal dietary intake. ${ }^{15}$

In Western countries, 3 to $34 \%$ of the population miss eating breakfast ${ }^{19,20}$; numerous factors can influence skipping breakfast, among them socioeconomic status, ${ }^{21}$ perception of lack of palatable choice, ${ }^{22}$ economics, ${ }^{23}$ and misconceptions regarding what constitutes a healthy meal..$^{22,24,25}$ In addition, breakfast skipping is revealed more among girls, older adolescents, and persons from low socioeconomic groups. ${ }^{26,27}$ Published research into the putative reasons for and prevalence of skipping breakfast in dance populations is scarce. However, research examining the energetic deficiencies in dancers' diet allows for the probability that breakfast skipping is prevalent in this cohort. ${ }^{28-30}$

Glycemic index (GI) is defined as the incremental area under the blood glucose response curve elicited by $50 \mathrm{~g}$ available $\mathrm{CHO}$ in a portion of food. ${ }^{31}$ This quantity is then compared to a standard reference food: the rise in blood glucose caused by consuming pure glucose or white bread also containing $50 \mathrm{~g}$ of $\mathrm{CHO} .{ }^{31}$ Thus GI, expressed as a percentage, relates more to the quality than the quantity of $\mathrm{CHO}$ in foods. Per gram of $\mathrm{CHO}$, foods with a high GI produce a high peak in postprandial blood glucose and a greater overall blood glucose response during the first 2 to 3 hours after consumption than do foods with a low GI. ${ }^{32}$

Researchers have examined the importance of incremental $\mathrm{CHO}$ feedings and its effect on glycogen storage and found that the adjustment of feeding patterns with attention to GI may offer significant advantages to athletes. ${ }^{33-35}$ An addendum to the original list included the concept of glycemic load (GL) based on work done at Harvard University. ${ }^{36,37} \mathrm{GL}$ is equal to the GI of a food times the number of grams of net $\mathrm{CHO}$ per serving. GL correlates more directly to the level of blood glucose changes than GI alone. GL quantifies the overall glycemic effect of a food serving. Foods that have a low GL normally have a low GI. However, foods with an intermediate or high GL range from very low to very high GI. 
TABLE 1. Demographic Characteristics of Study Participants $(n=10)$

\begin{tabular}{ll}
\hline Age & $20.3 \pm 1.5 \mathrm{yrs}$ \\
Weight & $62 \pm 5.2 \mathrm{~kg}$ \\
Height & $1.75 \pm 0.01 \mathrm{~m}$ \\
\hline
\end{tabular}

In regard to affect, the Feeling Scale (FS) ${ }^{41}$ is a psychometric scale that examines not "what" but gives context to "how" one feels as a result of exertion. FS has been used in sport and exercise psychology as a dichotomous measure of pleasure-displeasure. ${ }^{38}$

Little research has been conducted experimentally on the effects of GI in the feeding patterns of dancers; however, it has been suggested that these indices could offer a guideline for nutritional planning in this population.,39 No known work has been published utilizing psychometric measures that reveal how a dancer feels as a result of dietary intervention. The aim of this study was to examine how carbohydrate consumption (CHO) or fasting (FAST) impacted blood glucose and the Feeling Scale.

\section{METHODOLOGY}

\section{Participants}

Ten $(n=10)$ physically healthy female contemporary dance students volunteered to participate in this study. All participants were currently taking daily dance classes four to six times per week for at least $4 \mathrm{hrs}$ a day and were injury free at the time of the study. The study took place in October of the first semester of the academic year. Table 1 shows anthropometric values for all participants.

Participants were recruited via a billboard at the dance school's health department. A group meeting was used to present the aims of the study, and if individuals volunteered to take part in the study, they were asked to sign informed consent and Par-Q forms. Participants were excluded for contraindications such as chronic smoking, diet manipulation, preexisting gastrointestinal conditions, and medication or drugs known to influence lipid or $\mathrm{CHO}$ metabolism. All female participants reported regular menses and none were knowingly pregnant. In accordance with the Data Protection Act, participants were entered as a code number rather than by name for identification protection, and only the principal technician had access to the participants' personal information. The University of Wolverhampton gave ethical approval for the study.

\section{Procedure}

A balanced crossover experimental design was implemented, and thus participants served as their own control. On testing days, participants reported to the facilities in the morning, 1 hour before tests commenced, after reporting an overnight fast $(\geq 12 \mathrm{hr}$ ). After collection of the baseline blood samples and the FS questionnaire was com- pleted, the participants consumed either water (FAST) or moderate glycemic index energy (MGI) bar. The MGI bar contained $47.3 \mathrm{~g}$ of $\mathrm{CHO}, 2.1 \mathrm{~g}$ of fat, and $9.6 \mathrm{~g}$ of protein. The bar had to be consumed within 15 to 20 minutes dependant on dancer's self-chosen warm-up. Participants were free to drink water ad libitum. Blood capillary and FS data were collected at baseline $(20 \mathrm{~min}$ before the commencement of the dance class) and at 30 and 60 minutes of the dance class.

Blood glucose was measured using an Accu-chek Compact Plus (Roche Diagnostics, Mannheim, Germany). It is possible that capillary blood sampling may be less precise than venous, because of potential contamination of blood samples with interstitial fluid due to "milking" of the finger. However, in studies where simultaneous venous and capillary blood was taken, the opposite was found to be the case. ${ }^{40}$

The Hardy and Rejeski Feeling Scale (FS) $)^{41}$ is an 11-point single-item bipolar rating scale ranging from -5 (very bad) to +5 (very good). Participants were asked to rate how they felt at that particular moment. FS has the advantage of most other self-report scales of being easily and quickly administered during exercise, thus turnover from test to return to class was minimal ( \pm 2 min per participant).

\section{Dance Class}

As the participants were already familiar with the contemporary dance class and instructor, and no preliminary test or acclimatization protocol was necessary. The students were observed in their normal class by the principal researcher on three occasions prior to testing. This gave information as to the pace and flow of the class in order to know the best timing to remove students from class. The class consisted of a stationary warm-up in the center, followed by combinations of floor work and finally a series of technical compositions increasing both in intensity and duration, including moving along the diagonal and jumping sequences.

\section{Statistical Analysis}

Descriptive statistics (mean $\pm \mathrm{SD}$ ) were calculated for blood glucose and FS scores. Repeated measures ANOVA (group $\times$ time) and Scheffe post hoc tests were used to analyze the intervention effect on blood glucose and FS. Statistical significance was set at $p<0.05$. In addition, to further interpret any differences between means, effect sizes (partial eta ${ }^{2}$ ) were calculated and interpreted based on the criteria of Cohen ${ }^{42}$ where 0.1 is a small effect, 0.25 is a medium effect, and 0.4 is a large effect. Regression analyses were used to assess the relationship between blood glucose and FS.

\section{RESULTS}

For blood glucose parameters, there was no main effect of group $\times$ time interactions for blood glucose, though there 
A

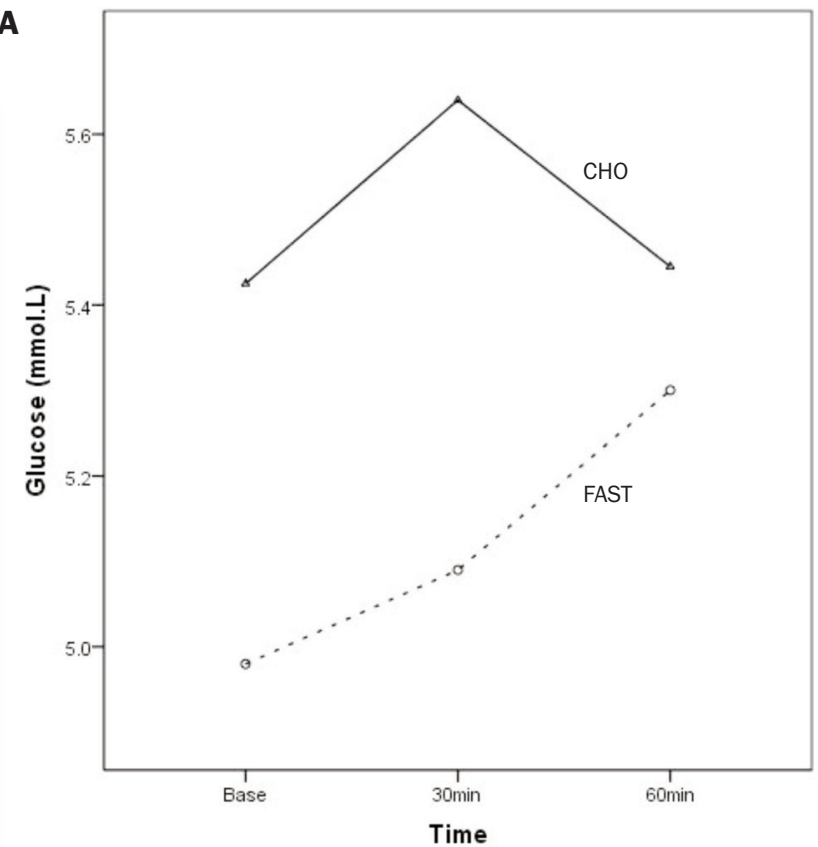

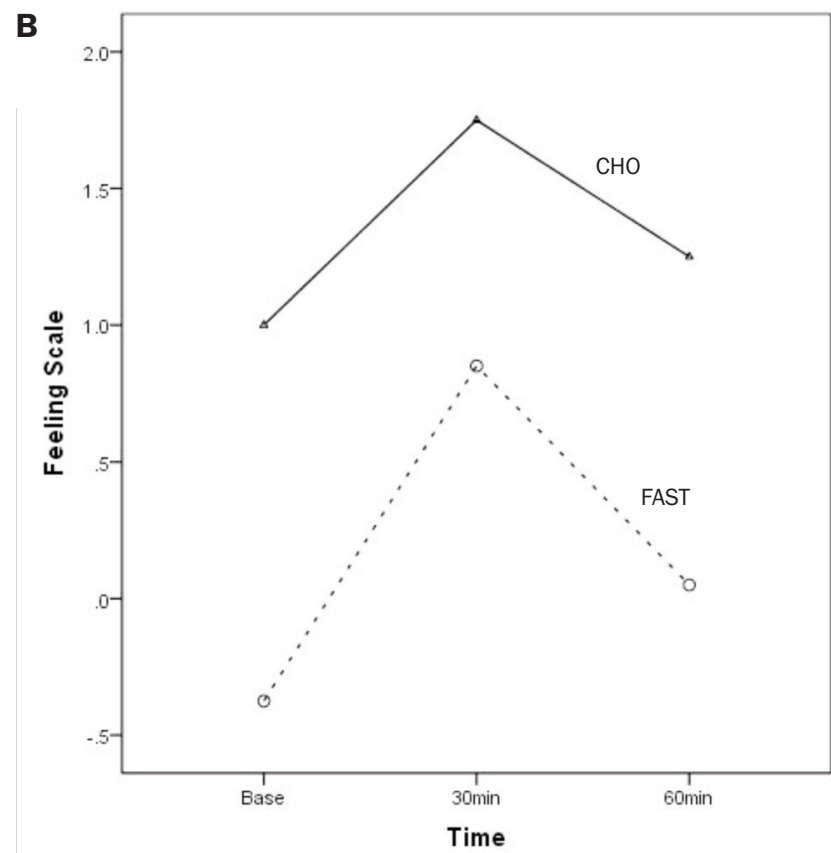

FIGURE 1. Mean glucose concentrations (panel A) and changes in pleasure-displeasure FS values (panel B) at rest (baseline) and at $30 \mathrm{~min}$ and $60 \mathrm{~min}$ of dance class after ingestion of an MGI energy bar (CHO, intervention group, solid line) or water (FAST, control group, dashed line).

was a significant group $\times$ time interaction in blood glucose levels $\left(F_{1,114}=6.273 ; p=0.014\right)$. MGI consumption resulted in a gradual rise in blood glucose concentrations, peaking at 30 minutes post consumption (Fig. 1A).

For the Feeling Scale, a similar pattern was noted. There was no main effect, but group $\times$ time interaction reported significant changes in FS $\left(F_{1,114}=9.891 ; p=0.002\right)$ with MGI consumption resulting in greater scores, peaking at $30 \mathrm{~min}$ utes and then decreasing by 60 minutes (Fig. 1B).

Linear and logarithmic regression analyses of the blood glucose concentration and FS data reported a moderate significant relationship $\left(F_{1,119}=3.232 ; p=0.038, r=0.262\right)$.

\section{DISCUSSION}

The main purpose of this study was to examine the effects of ingesting an MGI CHO energy bar on physiological parameters and pleasure-displeasure affect in an experimental protocol implemented during an actual dance class. The ingestion of an MGI CHO compared with ingestion of water prior to dance class had a significantly positive impact on blood glucose levels during the subsequent dance class. Exercise creates a powerful stimulus for blood glucose uptake into skeletal muscles; in a post-absorptive state (when energy needs are met solely by reserves and the intestines are empty), blood glucose can constitute 15 to $30 \%$ of the energy requirement of the working muscle during moderate exercise and upwards of $40 \%$ during high intensity events. ${ }^{43}$ Research has shown that $\mathrm{CHO}$ ingestion prior to exercise with either low or high GI foods maintained higher blood glucose concentrations ${ }^{44}$ and decreased plasma lactate concentrations during exercise or post exercise. ${ }^{45}$

There were differences seen in blood glucose levels at baseline between both groups; however, post-hoc results revealed these were not significant. Further, results revealed that, in the FAST trial, blood glucose concentrations increased rapidly from baseline to $30 \mathrm{~min}$, with a transient decline from the $30 \mathrm{~min}$ to $60 \mathrm{~min}$ time points, which are comparable to previous studies in athletes. ${ }^{46,47}$ In the $\mathrm{CHO}$ trial, the rise from baseline to $30 \mathrm{~min}$ was minimal, with a subsequent marginal decline in glucose level from $30 \mathrm{~min}$ to the final time point. Neither group's blood glucose concentrations dropped below baseline measurements. Other studies confirm similar findings in which water, when compared with a high GI meal, produced an increase in postprandial glycemic response. ${ }^{48}$ Others have indicated a rapid increase in hyperinsulinemia, with increased glucose uptake and decreased free fatty acids availability as a possible cause. ${ }^{49,50}$ Wyon and Redding ${ }^{51}$ have shown that that the center phase of a dance class is an intermittent form of exercise that does not place significant stress on the aerobic system. Thus in class, high-intensity intermittent physical activity (HIIT) conceivably occurs only in the final stages of class via center, across the floor, and jumping combination. Furthermore, evidence would suggest that muscle glycogen contribution to energy production decreases over time during exercise of moderate to high intensity, ${ }^{52}$ while HIIT, or start-and-stop types of physical performance, favor lipid oxidation. ${ }^{53}$ However, in the current study this could not be confirmed, as only blood glucose and neither glucose kinetics nor lipid oxidation was measured. 
The second aim of the present study was to examine whether skipping breakfast had an effect on dancers' pleasure-displeasure state during class. Previous research has shown that blood glucose influences mood, with a low blood glucose congruent with a more negative mood. ${ }^{54}$ Moreover, in studies with cognitively demanding tasks, as seen in the present study, falling levels of blood glucose have been associated with feeling less energetic. ${ }^{55}$ Within the present study, overall ratings of pleasure were higher in the $\mathrm{CHO}$ trial, when compared with the FAST trial. At baseline, the $\mathrm{CHO}$ group felt neither pleasure nor displeasure, while the FAST group felt displeasure. In both groups, pleasure ratings became more positive during the second time point $(30 \mathrm{~min})$, followed by a decline in pleasure for both trials towards the final time point $(60 \mathrm{~min})$. Our results are similar to those reported by Backhouse et al., ${ }^{52}$ who examined the influence of $\mathrm{CHO}$ beverage ingestion on affect (pleasure-displeasure) and perceived exertion during a high-intensity intermittent soccer match. ${ }^{56}$

\section{CONCLUSION}

The aim of this study was to examine the effect of MGI supplementation on blood glucose and the pleasure-displeasure affect due to dietary intervention during a dance class. Although often suggested among colleagues in dance medicine and science, there has been little scientific evidence published to support meal manipulation within the dance population, with select food items for this single purpose. This study established that manipulating the student dancers' diet towards food items rich in complex carbohydrates contributed to the overall impact of blood glucose levels. The current research thus corroborates the current tenet that choice of macronutrient intake - in this case, $\mathrm{CHO}$ with an MGI value-confers a discernible effect on blood glucose levels.

\section{REFERENCES}

1. Wyon MA, Abt G, Redding E, et al. Oxygen uptake during modern dance class, rehearsal, and performance. J Dance Med Sci. 2005;9(1):36.

2. Haight H. Morphologic, physiologic, and functional interactions in elite female ballet dancers. Med Probl Perform Art. 1998;13(1):4-13.

3. Koutedakis Y, Myszkewycz L, Soulas D, et al. The effects of rest and subsequent training on selected physiological parameters in professional female classical dancers. Int J Sports Med. 1999; 20(6):379-383.

4. Campbell C, Prince D, Braun M, et al. Carbohydrate-supplement form and exercise performance. Int J Sport Nutr Exerc Metab. 2008;18:179-190.

5. Gollnick PD. Metabolism of substrates: energy substrate metabolism during exercise and as modified by training. Fed Proc. 1985;44(2):353-357.

6. Walberg-Rankin J. Dietary carbohydrate as an ergogenic aid for prolonged and brief competitions in sport. Int J Sport Nutr. 1995;5(suppl):S13-28.

7. Asp N-G. Classification and methodology of food carbohydrates as related to nutritional effects. Am J Clin Nutr. 1995;61(4 suppl):930S-937S.
8. Asp N-G, Cummings J. Carbohydrates in Human Nutrition. FAO Food and Nutrition Paper-66. Food and Agriculture Organisation of the United Nations, 1997.

9. Kerksick C, Harvey T, Stout J, et al. International Society of Sports Nutrition position stand: Nutrient timing. J Int Soc Sports Nutr. 2008;5:17.

10. Benson J, Gillien DM, Bourdet K, Loosli AR. Inadequate nutrition and chronic calorie restriction in adolescent ballerinas. Physician Sportsmed. 1985;13(10):79-80.

11. Calabrese LH, Kirkendall DT. Nutritional and medical considerations in dancers. Clin Sports Med. 1983;2:539-548.

12. Culnane C, Deutsch D. Dancer disordered eating: comparison of disordered eating behavior and nutritional status among female dancers. J Dance Med Sci. 1998;2(3):95-101.

13. Dotti A, Fioravanti M, Balotta M, et al. Eating behavior of ballet dancers. Eating Weight Disord. 2002;7(1):60-67.

14. Frusztajer NT, Dhuper S, Warren MP, et al. Nutrition and the incidence of stress fractures in ballet dancers. Am J Clin Nutr. 1990;51(5):779-783.

15. Hamilton LH, Brooks-Gunn J, Warren MP. Nutritional intake of female dancers: a reflection of eating problems. Int $J$ Eating Disord. 1986;5(5):925-934.

16. Kaufman BA, Warren MP, Dominguez JE, et al. Bone density and amenorrhea in ballet dancers are related to a decreased resting metabolic rate and lower leptin levels. J Clin Endocrinol Metab. 2002;87(6):2777-2783.

17. Loosli A, Gillien D, Benson J, Bourdet K. Inadequate nutrition and chronic caloric restriction among ballet dancers. Med Sci Sports Exerc. 1985;17(2):201.

18. Koutedakis Y, Jamurtas A. The dancer as a performing athlete: physiological considerations. Sports Med. 2004;34(10):651-661.

19. Dialektakou K, Vranas P. Breakfast skipping and body mass index among adolescents in Greece: whether an association exists depends on how breakfast skipping is defined. J Am Diet Assoc. 2008;108(9):1517-1525.

20. Rampersaud G, Pereira M, Girard B, et al. Breakfast habits, nutritional status, body weight, and academic performance in children and adolescents. J Am Diet Assoc. 2005;105(5):743-760.

21. Hallstrom L, Vereecken CA, Ruiz JR, et al. Breakfast habits and factors influencing food choices at breakfast in relation to sociodemographic and family factors among European adolescents: the HELENA Study. Appetite. 2011;56(3):649-657.

22. Warren E, Parry O, Lynch R, Murphy S. If I don't like it, then I can choose what I want?: Welsh school children's accounts of preference for and control over food choice. Health Promotion Int. 2008;23(2):144-151.

23. Sweeney N, Horishita N. The breakfast-eating habits of inner city high school students. J Sch Nurs. 2005;21(2):100-105.

24. Alexander K, Ventura E, Spruijt-Metz D, et al. Association of breakfast skipping with visceral fat and insulin indices in overweight Latino youth. Obesity. 2009;17(8):1528-1533.

25. Devaraj S, Wang-Polagruto J, Polagruto J, et al. High-fat, energydense, fast-food-style breakfast results in an increase in oxidative stress in metabolic syndrome. Metabolism. 2008;57(6):867-870.

26. Richter M, Erhart M, Vereecken CA, et al. The role of behavioural factors in explaining socio-economic differences in adolescent health: a multilevel study in 33 countries. Soc Sci Med. 2009;69(3):396-403.

27. Vereecken C, Dupuy M, Rasmussen M, et al. Breakfast consumption and its socio-demographic and lifestyle correlates in schoolchildren in 41 countries participating in the HBSC study. Int J Public Health. 2009;54(suppl 2):180-190.

28. Dahlstrom M, Jansson E, Nordevang E, Kaijser L. Discrepancy between estimated energy intake and requirement in female dancers. Clin Physiol. 1990;10(1):11-25.

29. Patterson E, Smith R, Everett J, Ptacek J. Psychosocial factors as predictors of ballet injuries: interactive effects of life stress and social support. J Sport Behav. 1998;21(1):101-113. 
30. Wagenmakers AJ. Protein and amino acid metabolism in human muscle. Adv Exp Med Biol. 1998;441:307-319.

31. Jenkins D, J Wolever TM, Taylor RH, et al. Glycemic index of foods: a physiological basis for carbohydrate exchange. Am J Clin Nutr. 1981;34(3):362-366.

32. Foster-Powell K, Holt SH, Brand-Miller JC. International table of glycemic index and glycemic load values: 2002. Am J Clin Nutr. 2002;76(1):5-56.

33. Burke LM, Collier GR, Davis PG, et al. Muscle glycogen storage after prolonged exercise: effect of the frequency of carbohydrate feedings. Am J Clin Nutr. 1996;64:115-119.

34. Li TL, Wu CL, Gleeson M, Williams C. The effects of pre-exercise high carbohydrate meals with different glycemic indices on blood leukocyte redistribution, IL-6, and hormonal responses during a subsequent prolonged exercise. Int J Sport Nutr Exerc Metab. 2004;14(6):647-656.

35. Sparks MJ, Selig SS, Febbraio MA. Pre-exercise carbohydrate ingestion: effect of the glycemic index on endurance exercise performance. Med Sci Sports Exerc. 1998;30(6):844-849.

36. Liu S, Willett WC, Stampfer MJ, et al. A prospective study of dietary glycemic load, carbohydrate intake, and risk of coronary heart disease in US women. Am J Clin Nutr. 2000;71(6):14551461.

37. Brand-Miller J, McMillan-Price J, Steinbeck K, Caterson I. Carbohydrates - the good, the bad and the whole grain. Asia Pac J Clin Nutr. 2008;17(suppl 1):16-19.

38. Backhouse SH, Bishop NC, Biddle SJ, Williams C. Effect of carbohydrate and prolonged exercise on affect and perceived exertion. Med Sci Sports Exerc. 2005;37:1768-1773.

39. Gonen E, Madar Z, Wexler ID, Dolev E. Unique nutritional sspects associated with professional dancing. In: Lebenthal E, Shapira N, eds. Nutrition in the Female Life Cycle. Jerusalem: ISAS Inernational Seminars Ltd.; 2000: pp27-37.

40. Wolever T, Bolognesi C. Source and amount of carbohydrate affect postprandial glucose and insulin in normal subjects. J Nutr. 1996;126(11):2798.

41. Hardy CJ, Rejeski WJ. Not what, but how one feels: the measurement of affect during exercise. J Sport Exerc Psychol. 1989;11:304317.

42. Cohen J. A power primer. Psychol Bull. 1992;112(1):155-159.

43. Wahren J, Felig P, Ahlborg G, Jorfeldt L. Glucose metabolism during leg exercise in man. J Clin Invest. 1971;50(12):2715.

44. DeMarco HM, Sucher KP, Cisar CJ, Butterfield GE. Pre-exercise carbohydrate meals application of glycemic index. Med Sci Sports Exerc. 1999;31(1):164-170.

45. Stannard S, Thompson M, Miller B. The effect of glycemic index on plasma glucose and lactate levels during incremental exercise. Int J Sport Nutr. 2000;10:51-61.

46. Brotherhood JR. Nutrition and sports performance. Sports Med. 1984;1:350-389.

47. Wong SHS, Chan OW, Chen YJ, et al. Effect of preexercise glycemic-index meal on running when $\mathrm{CHO}$-electrolyte solution is consumed during exercise. Int J Sport Nutr Exerc Metab. 2009; 19:222-242.

48. Kirwan JP, Cyr-Campbell D, Campbell WW, et al. Effects of moderate and high glycemic index meals on metabolism and exercise performance. Metabolism. 2001;50(7):849-855.

49. Costill DL, Coyle E, Dalsky G, et al. Effects of elevated plasma FFA and insulin on muscle glycogen usage during exercise. $J$ Appl Physiol. 1977;43(4):695-699.

50. Febbraio M, A Keenan J, Angus DJ, et al. Preexercise carbohydrate ingestion, glucose kinetics, and muscle glycogen use: effect of the glycemic index. J Appl Physiol. 2000;89:1845-1851.

51. Wyon MA, Redding E. Physiological monitoring of cardiorespiratory adaptations during rehearsal and performance of contemporary dance. J Strength Cond Res. 2005;19(3):611-614.

52. Romijn JA, Coyle EF, Sidossis LS, et al. Substrate metabolism during different exercise intensities in endurance-trained women. J Appl Physiol. 2000;88(5):1707-1714.

53. Tremblay A, Simoneau J-A, Bouchard C. Impact of exercise intensity on body fatness and skeletal muscle metabolism. Metabolism. 1994;43(7):814-818.

54. Gonder-Frederick LA, Cox DJ, Bobbitt SA, Pennebaker J. Mood changes associated with blood glucose fluctuations in insulindependent diabetes mellitus. Health Psychol. 1989;8(1):45-49.

55. Owens DS, Parker PY, Benton D. Blood glucose influences mood following demanding cognitive tasks. Physiol Behav. 1997;62:471478.

56. Backhouse SH, Ali A, Biddle SJ, Williams C. Carbohydrate ingestion during prolonged high-intensity intermittent exercise: impact on affect and perceived exertion. Scand J Med Sci Sports. 2007;17(5):605-610. 